\title{
A Novel Internal Dual-Polarized EBG Antenna for Indoor Reception of UHF Terrestrial Digital TV Broadcasting
}

\author{
Mohamed Sanad ${ }^{1}$ and Noha Hassan ${ }^{2}$ \\ ${ }^{1}$ Amant Antennas, Giza 12451, Egypt \\ ${ }^{2}$ Department of Biomedical Engineering and Systems, Cairo University, Giza 12613, Egypt
}

Correspondence should be addressed to Mohamed Sanad, msanad@hotmail.com

Received 1 March 2012; Revised 24 June 2012; Accepted 8 July 2012

Academic Editor: Safieddin Safavi-Naeini

Copyright (C) 2012 M. Sanad and N. Hassan. This is an open access article distributed under the Creative Commons Attribution License, which permits unrestricted use, distribution, and reproduction in any medium, provided the original work is properly cited.

\begin{abstract}
A novel internal antenna has been developed for indoor reception of UHF terrestrial digital TV broadcasting. The overall size of some configurations of the new antenna is less than $2 \mathrm{~cm}^{3}$, and its weight is less than $1 \mathrm{gm}$. It is made of a flexible material that can be bent or folded and shaped in any form. It is an unbalanced resonant antenna that does not need a matching circuit. The new antenna can be fully embedded inside TV sets or portable computers. It has a bandwidth of about $68 \%$. Thus, it can also cover the bands of GSM and CDMA, which is advantageous in case of portable computers. The new antenna is linearly polarized. It can be easily modified to be dual polarized by combining two orthogonal antennas with one or two feed points. The overall efficiency of some configurations of the new indoor digital TV receiving antenna is more than $80 \%$, and its peak gain is about $2 \mathrm{dBi}$ over the whole UHF band. The peak gain can be increased to more than $5 \mathrm{dBi}$ by adding EBG (electromagnetic bandgap) structures. The EBG structure also increases the efficiency to around $90 \%$.
\end{abstract}

\section{Introduction}

The start of terrestrial digital TV broadcasting may considerably reduce the need for on-roof directional receiving antennas and increase the use of indoor antennas. Most terrestrial digital TV broadcasting channels are in the UHF band. Of course, analogue TV indoor receiving antennas can still be used with digital TV indoor reception. The most common UHF indoor digital TV receiving antennas are loop antennas and triangular dipoles [1]. However, they have large sizes and they are not rigid on top of TV sets. Also, they are balanced antennas and, hence, they need baluns. Furthermore, they are sensitive to only one polarization and, therefore, they have a poor indoor performance. Moreover, they are pure electric field antennas and, hence, their performance is significantly deteriorated in vicinity of conductive objects such as concrete walls. In addition, conventional indoor TV receiving antennas cannot be used in multi-input (MI) configurations and techniques for space and/or polarization diversity. In order to overcome some of the above problems, other indoor TV receiving antennas have been developed and published as in [2-4].
However, they are also external antennas that have to be mounted outside TV sets and they are still large in size.

On the other hand, introduction of digital TV, built into portable computers, is expected in the near future. Since portable computers are getting smaller and smaller in size, they add volume limitations on digital TV antennas. Hence, it is very challenging to cover the whole UHF band of digital TV with a single small-size resonant antenna that can be integrated into portable computers or handsets. Therefore, matching circuits have been usually used to tune mobile TV antennas [5-8]. Matching circuits increase the complexity of the antenna and reduce the efficiency. In the mean time, cellular network radios have been already integrated into some modern laptop, notebook, and palmtop computers in order to give the user access to the Internet in areas not covered by WLANs. The problem is that the frequency bands of GSM (824-894 MHz) and UHF digital TV (470$862 \mathrm{MHz}$ ) are overlapping. As a result, there will be a severe interference between their antennas.

In this research, a novel internal antenna that can solve all the above problems is developed for indoor reception of UHF 
terrestrial digital TV broadcasting. The new antenna covers a bandwidth of around $68 \%$. It resonates from $470 \mathrm{MHz}$ to more than $960 \mathrm{MHz}$. Hence, a single antenna can cover all the bands of UHF digital TV $(470-862 \mathrm{MHz}), 700 \mathrm{MHz}$ WiMax, CDMA/GSM800 (824-894 MHz), and E-GSM900 $(880-960 \mathrm{MHz})$. The new antenna is resonant antenna that does not need matching circuits. Furthermore, it does not need an additional extended ground plane or any other components. Thus, it can be mounted anywhere inside or outside any TV set or any portable computer because the antenna does not use a part of the equipment as an extended ground plane as usually happens with internal antennas. Moreover, the new antenna is made of a flexible material and it can be bent and/or folded in different forms. The new antenna can be fully embedded inside TV sets and portable computers. Actually, it can be used as internal, external or partially internal, and partially external antenna. In order to increase the peak gain of the antenna, an EBG (electromagnetic bandgap) structure has been used [9]. The new antenna is linearly polarized. It can also be modified in order to make it sensitive to two orthogonal polarizations, which is a very important factor in all indoor applications. Dual-polarized antennas can have a single feed point or two different feed points in order to be used in multi-input, multioutput (MIMO) configurations.

\section{Geometry of the New Antenna}

Figure 1 shows the geometry of the new developed UHF digital TV antenna. The new antenna consists of two narrow printed metallic arms connected together by a shorting metallic strip. The two arms may be parallel to each other or may have any angle between them. The length of the short arm is $L_{1}$, and its width is $W_{1}$ while the length of the long $\operatorname{arm}$ is $L_{2}$, and its width is $W_{2}$. The thickness of the antenna is $T$, and it is fed with a coaxial feed at a distance $F$ from the shorted edge. The two arms of the antenna can have equal or unequal widths $W_{1}$ and $W_{2}$. Furthermore, the two arms can be shaped in different ways in order to optimize the antenna performance. As shown in Figure 1, each arm has a set of slots having different configurations. These slots can be circular, rectangular, square, or have other shapes. The arm lengths of the new antenna, especially the length of the short arm, are the main parameters that determine the operating frequency of the antenna. The feed location is adjusted in each configuration in order to improve the return loss as much as possible. The bandwidth, the peak gain, and the efficiency of the antenna are mainly determined by the widths of the two arms, the angle between them, the thickness of the antenna and the configurations of the slots which are all optimized together in order to enhance the antenna performance, especially the bandwidth. The basic concept of using such slots to increase the antenna bandwidth was initially used in E-shaped antennas as explained in [10], where only 2 of such slots were utilized. Thus, this new antenna is an extension to the concept of E-shaped antennas, which were originally developed by the authors of this paper [11].

Different prototypes of the new digital TV antenna have been designed, manufactured, and tested. The results of

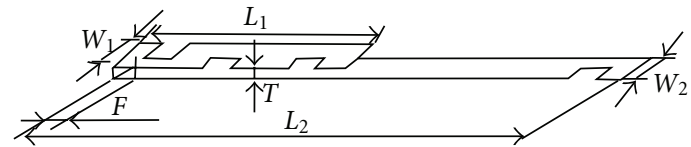

Figure 1: Geometry of the new wideband resonant antenna.

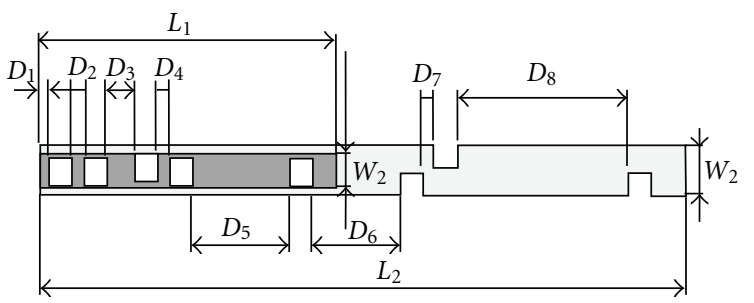

(a) Top view

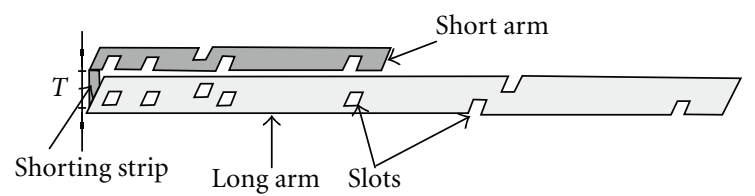

(b) $3 \mathrm{D}$ view

Figure 2: The selected sample antenna configuration.

TABLE 1

\begin{tabular}{lccccccc}
\hline$D_{1}$ & $D_{2}$ & $D_{3}$ & $D_{4}$ & $D_{5}$ & $D_{6}$ & $D_{7}$ & $D_{8}$ \\
\hline $5 \mathrm{~mm}$ & $10 \mathrm{~mm}$ & $15 \mathrm{~mm}$ & $5 \mathrm{~mm}$ & $45 \mathrm{~mm}$ & $35 \mathrm{~mm}$ & $5 \mathrm{~mm}$ & $75 \mathrm{~mm}$
\end{tabular}

a selected sample antenna configuration will be presented. The sample is made of a flexible printed material "PET" with a dielectric constant $\varepsilon_{r}=3.5$ and a tangent loss $\delta=0.015$. The geometry of the selected antenna configuration is shown in Figure 2. The two arms of the selected sample antenna are parallel to each other. The length $L_{1}$ of the short arm is $11.5 \mathrm{~cm}$ while the length $L_{2}$ of the long arm is $25 \mathrm{~cm}$. The width $W_{1}$ of the short arm is $2.6 \mathrm{~mm}$ while the width $W_{2}$ of the long arm is $3.5 \mathrm{~mm}$, and the antenna thickness $T$ is $2 \mathrm{~mm}$. The overall size of the antenna is $25 \times 0.35 \times 0.2=1.75 \mathrm{~cm}^{3}$, and its weight is less than $1 \mathrm{gm}$. It should be noted that this is the overall volume of the antenna because it does not require an additional ground plane, a matching circuit or any other components. It should also be noted that the length of the antenna can be reduced from $25 \mathrm{~cm}$ to $16 \mathrm{~cm}$ without any significant effect on the performance by folding the two ends of the antenna [12-14].

The slots in both arms are selected to be rectangular in shape. The length of each slot is $5 \mathrm{~mm}$ and its width is $2 \mathrm{~mm}$. The distance between the shorted edge and the first slot is $D_{1}$. The distances between the successive slots are $D_{2}, D_{3}, \ldots$, and $D_{8}$, respectively. The locations of the first five slots are similar in both arms. This means that the first five slots in the short arm are located exactly above the first five slots in the long arm. However, since the long arm is wider than the short arm, the first five slots are positioned close to the middle of the long arm forming rings while they are located at the edge of the short arm as shown in Figure 2(b). The values of $D_{1}, D_{2}, \ldots$, and $D_{8}$ are shown in Table 1. 


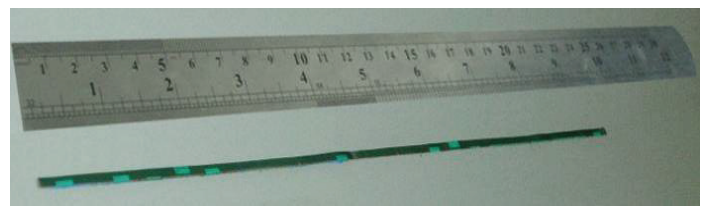

(a)

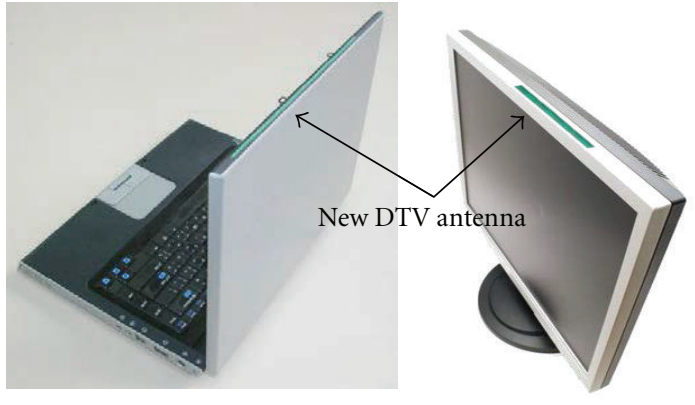

(b)

FIGURE 3: The new digital TV antenna prototype on the display rim of a portable computer and a digital TV set.

Figure 3 shows the first manufactured prototype in free space and while it is mounted on the display rim of a portable computer and a TV set. In this configuration, the new antenna has a minimum blockage by the TV set and the portable computer housing. This unique configuration is feasible with all portable computers and TV sets because the widths of the new antenna can always be made narrower than the width of the display rim of any portable computer and any TV set. Furthermore, the new antenna can be mounted anywhere because it does not use a part of the TV set or the portable computer as an extended ground plane as usually happens with internal antennas. Moreover, the new antenna does not need to be customized for any portable computer or any TV set because the effect of the housing of these sets on the antenna was found to be negligible [15].

The return loss and the radiation patterns of the new digital TV receiving antenna were numerically calculated using Zeland (http://www.zeland.com/) software package that utilizes the moment method. The above selected configuration and some other prototypes were also measured at IMST antenna labs in Germany [16] in order to verify the numerical simulations. Both numerical and experimental results of the above selected configuration will be presented in order to show the agreement between them. For the following configurations, only measured return losses and simulated patterns and efficiencies will be presented.

Figure 4 shows the calculated and the measured return loss of the new antenna. The measured return loss is less than $-6 \mathrm{~dB}$ from about $470 \mathrm{MHz}$ to $960 \mathrm{MHz}$ which is more than $68 \%$ bandwidth. This band can cover digital TV, GSM, and CDMA. Figure 5 shows the calculated and the measured peak gain of the antenna. The measured peak gain is higher than $0 \mathrm{dBi}$ over most of the band. This peak gain is much higher than MBRAI specifications of the UHF DVB-H mobile TV [17]. The calculated and the measured efficiency of the antenna is shown in Figure 6. The average efficiency is more than $45 \%$ over the whole band. The calculated radiation patterns at $600 \mathrm{MHz}$, as a sample frequency, are shown in Figure 7 . The corresponding measured patterns are shown in Figure 8.

From all the above results, it can be seen that there are some considerable differences between the calculated and measured results. This is because the used version of the software package assumes an infinite size substrate.

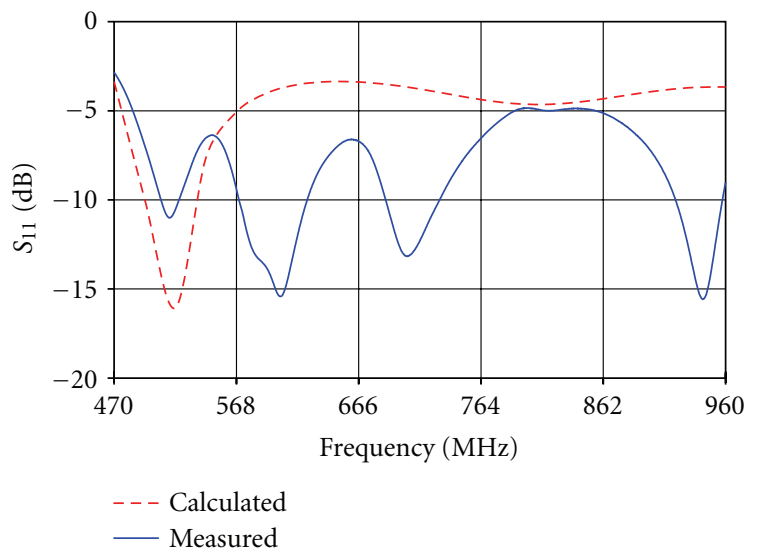

FIGURE 4: Calculated and measured return loss of the new antenna from $470 \mathrm{MHz}$ to $960 \mathrm{MHz}$.

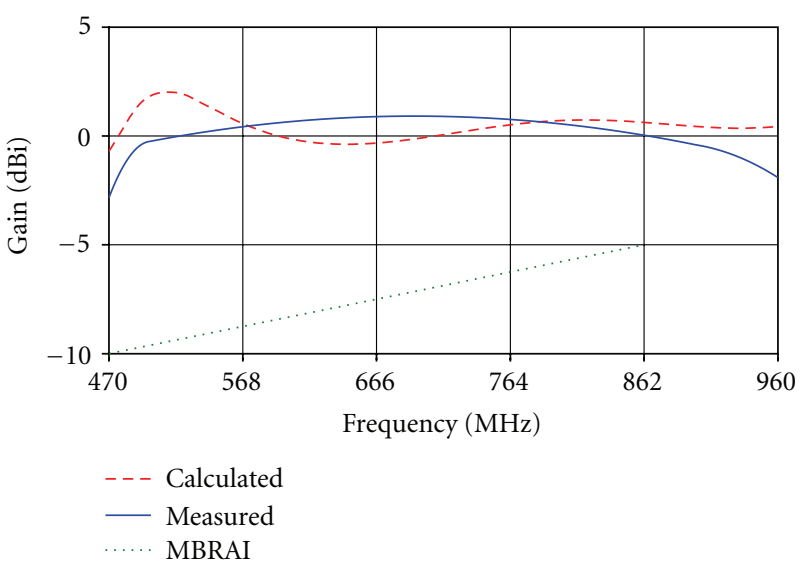

FIGURE 5: Calculated and measured peak gain of the new antenna from $470 \mathrm{MHz}$ to $960 \mathrm{MHz}$.

This assumption affects the accuracy of calculations when the width of the antenna substrate is very narrow as in the above antenna configurations. The difference between calculations and measurements is significant in efficiency curves because the efficiency depends on radiation patterns in all directions and in all planes and, hence, there is an accumulated reduction in the accuracy of calculations. This 


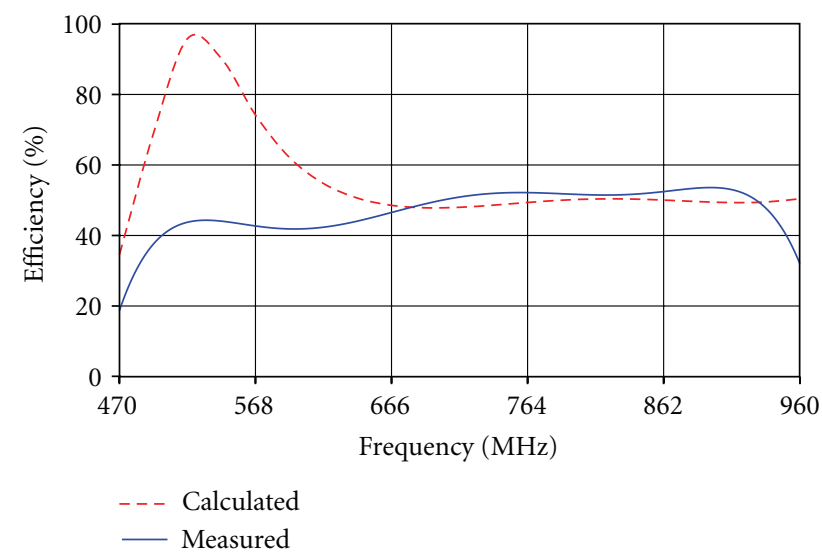

Figure 6: Calculated and measured efficiency of the new antenna from $470 \mathrm{MHz}$ to $960 \mathrm{MHz}$.
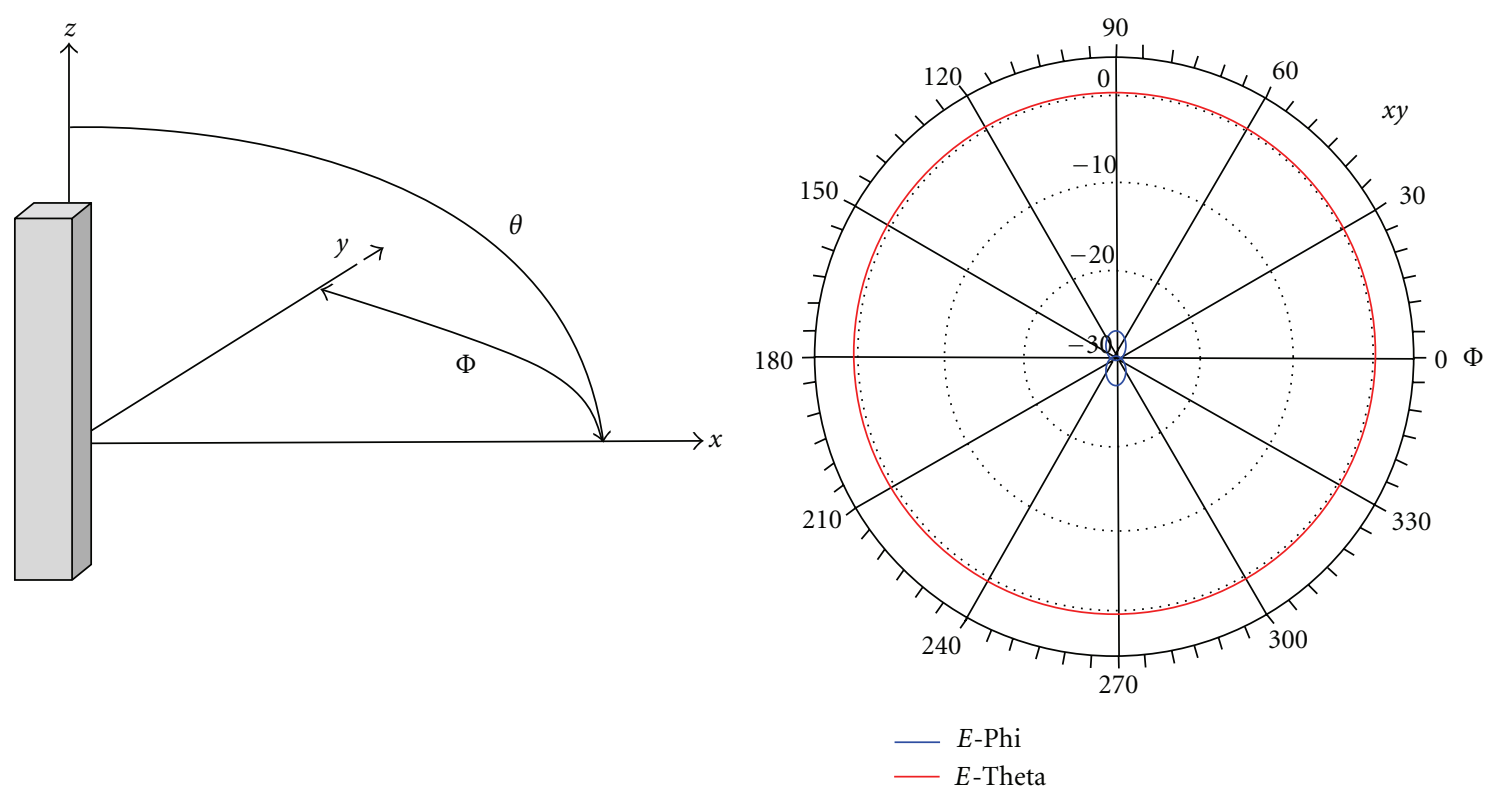

(a)

(b)

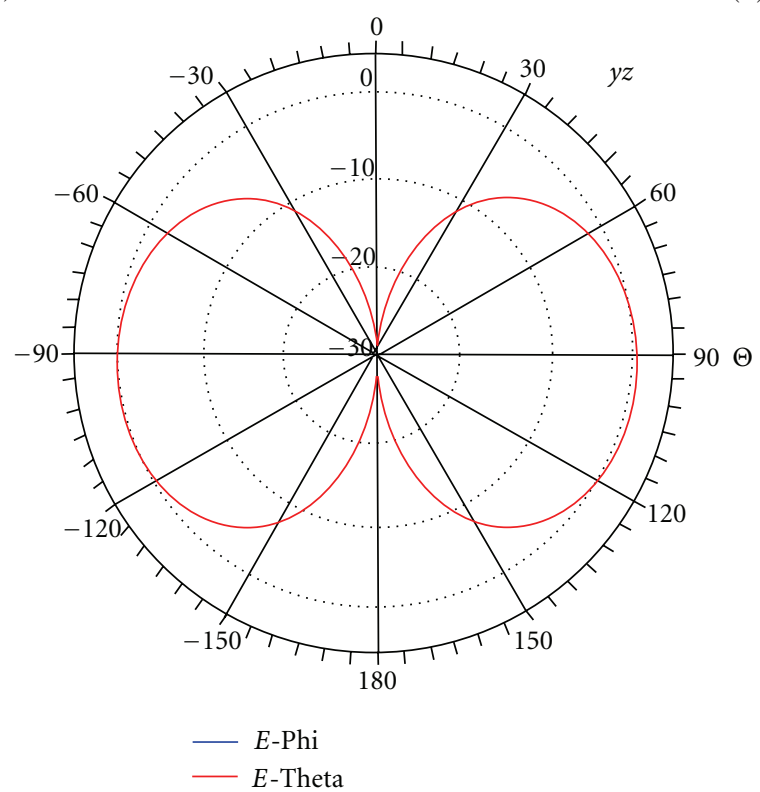

(c)

FIgURE 7: Calculated radiation patterns of the new antenna at $600 \mathrm{MHz}$. 


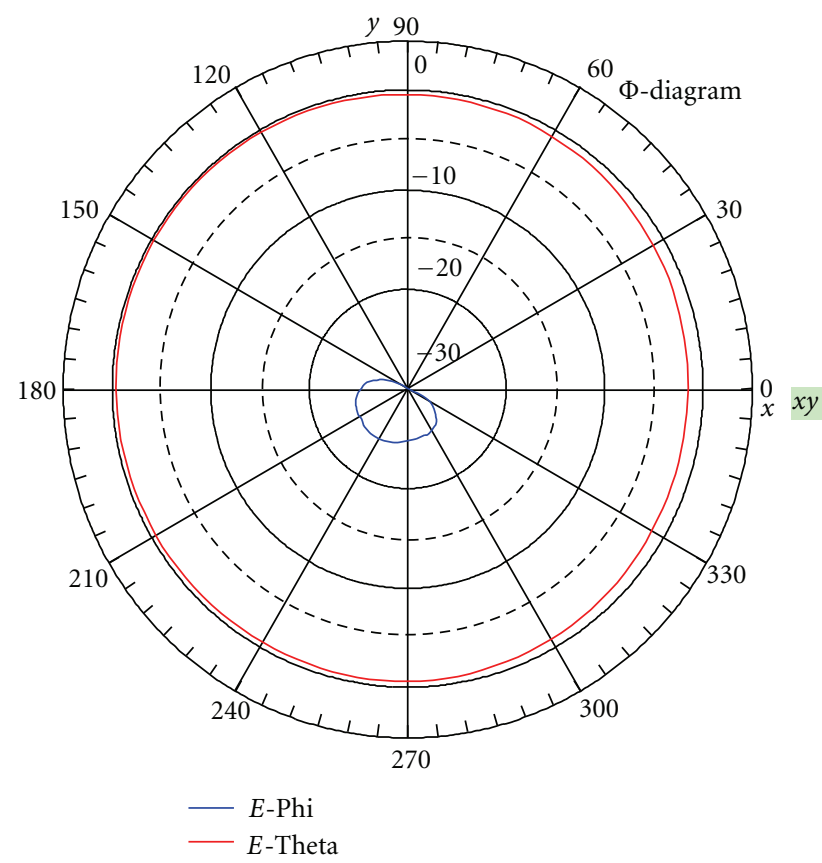

(a)

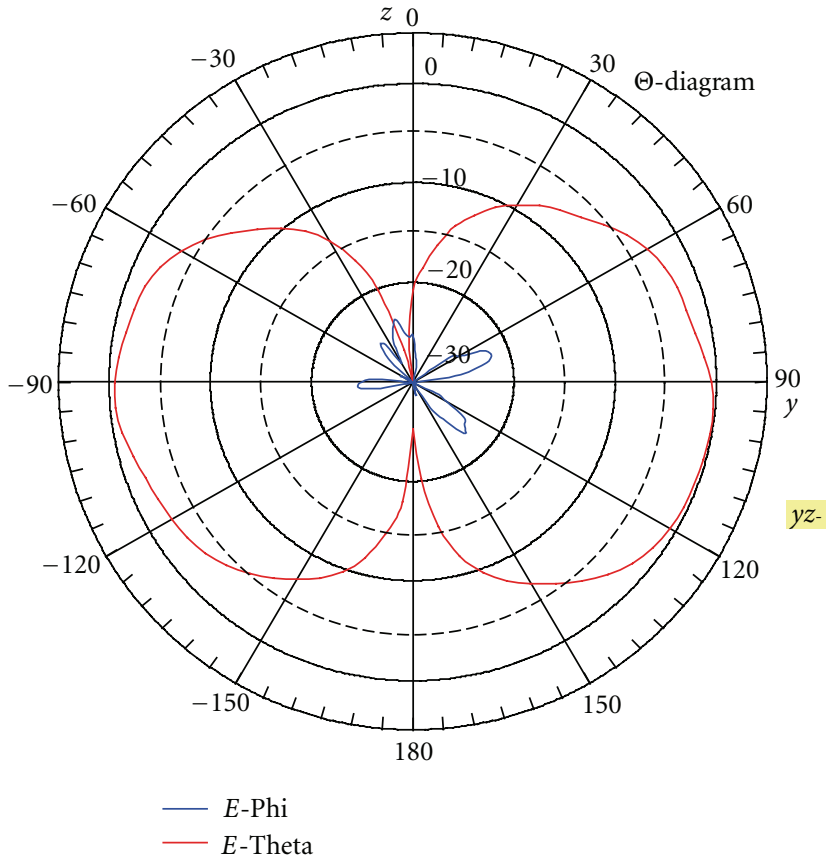

(b)

FIGURE 8: Measured radiation patterns of the new antenna at $600 \mathrm{MHz}$.

was more clear at the lower part of the frequency range where the antenna width is very narrow in terms of wavelengths.

\section{Increasing the Gain and the Efficiency}

As shown above, the new antenna could cover the whole frequency band of UHF digital TV, and its performance was much better than MBRAI specifications of the DVB-H mobile TV. However, for DVB-T (digital video broadcastingterrestrial TV), it will be desirable to further increase the gain and the efficiency of the new antenna. This can be easily achieved by increasing the width, and the thickness of the antenna as much as possible according to the available space in the portable computer or the TV set. A prototype of the antenna has been manufactured with an increased width and thickness. The dimensions of the increased-size antenna are: $L_{1}=11.5 \mathrm{~cm}, L_{2}=25 \mathrm{~cm}, W_{1}=8 \mathrm{~mm}$, $W_{2}=12 \mathrm{~mm}$, and $T=4 \mathrm{~mm}$. The overall size of the increased-size antenna is $25 \times 1.2 \times 0.4=12 \mathrm{~cm}^{3}$. Figure 9 shows the return loss of the increased-size antenna, which is around $-8 \mathrm{~dB}$ over the whole band. The overall efficiency of the increased-size antenna is shown in Figure 10. The average efficiency was more than $80 \%$ over the whole bandwidth. Figure 11 shows the peak gain of the new low-band antenna which is about $2 \mathrm{dBi}$ over the whole bandwidth. Figure 12 shows the radiation patterns of the new antenna at $600 \mathrm{MHz}$ which are omnidirectional with about $2 \mathrm{dBi}$ peak gain.

\section{Dual Polarized Antennas}

From Figure 12, it can be seen that the new antenna is sensitive to only one polarization while the orthogonal

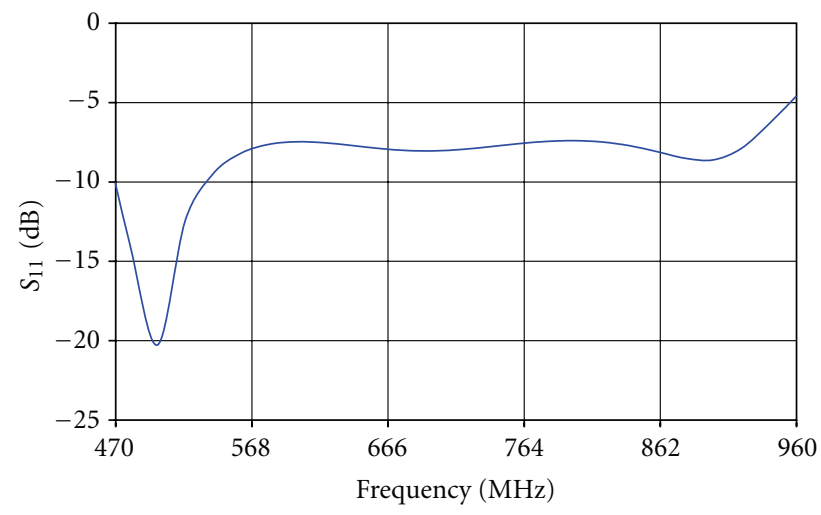

FIGURE 9: Return loss of the increased-size antenna.

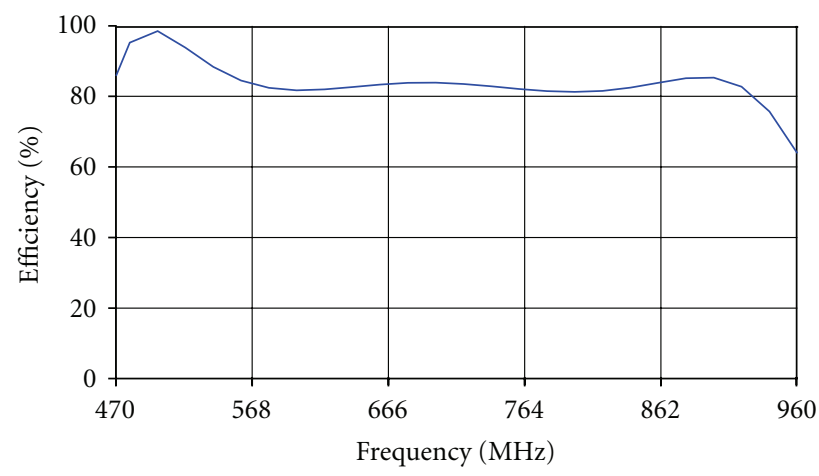

FIGURE 10: Efficiency of the increased-size antenna. 


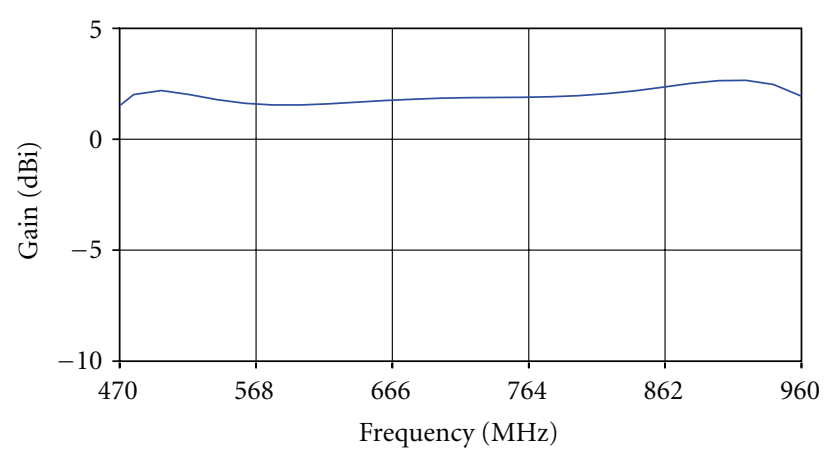

FIgURE 11: Peak gain of the increased-size antenna.

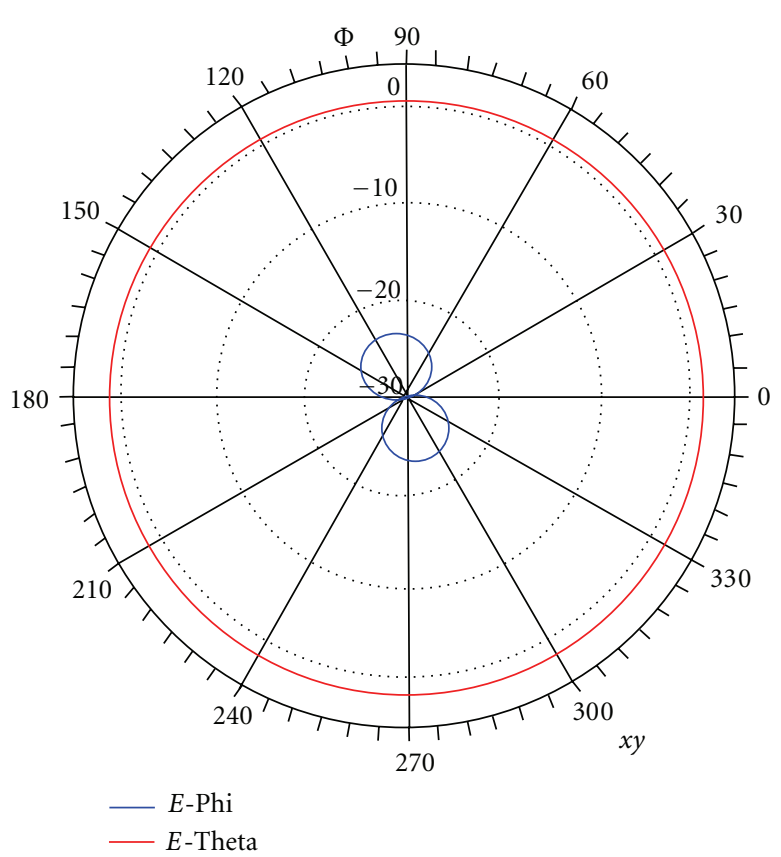

(a)

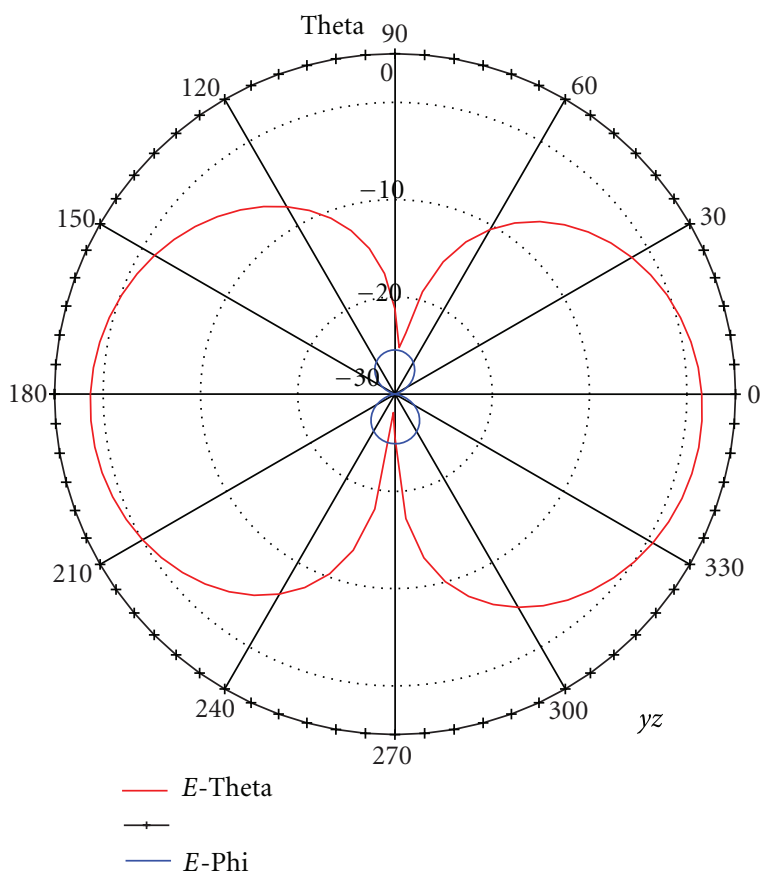

(b)

FIGURE 12: Radiation patterns of the increased-size antenna at $600 \mathrm{MHz}$.

polarization is negligible. However, the new antenna can be modified in order to make it sensitive to two perpendicular polarizations, which is a very important factor in all indoor applications. Dual-polarization can be accomplished by combining two orthogonal antennas with a common feed point as shown in Figure 13. The unique advantage of this dual-polarized antenna configuration is that it can still be mounted on the display rim of portable computers and TV sets and, thus, both polarizations of the antenna have a minimum blockage by the TV set and the portable computer housing. As mentioned above, this unique advantage is feasible with all portable computers and TV sets because the widths of both antenna polarizations can always be made narrower than the width of the display rim of any portable computer and any TV set.

The return loss of the dual-polarized antenna is shown in Figure 14 while the efficiency is shown in Figure 15. The efficiency is still higher than $80 \%$ over most of the band. The peak gain of the dual-polarized antenna is shown in Figure 16, and it is still higher than $2 \mathrm{dBi}$ over most of the band. Figure 17 shows the radiation patterns of the dualpolarized antenna at $600 \mathrm{MHz}$. It is clear from the figure that the antenna is equally sensitive to two orthogonal polarizations.

Dual-polarization can also be achieved by using two orthogonal antennas with two different feed points as shown in Figure 18. Again, this dual-polarized configuration has the unique advantage of being mounted on the display rim of portable computers and TV sets. This dual-feed configuration is important for multi-input, multioutput (MIMO) techniques. Since the interference between the orthogonal MIMO antennas is negligible, the return loss and the efficiency of the orthogonal antennas are not affected by the MIMO configuration, and they are almost the same as 


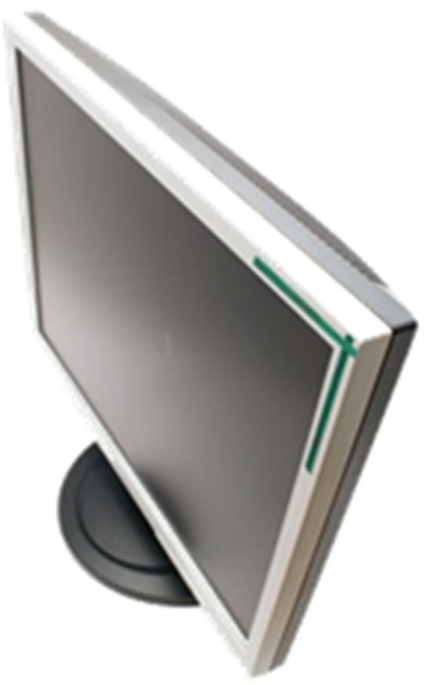

FIgURE 13: Two orthogonal antennas on a TV set with a common feed point.

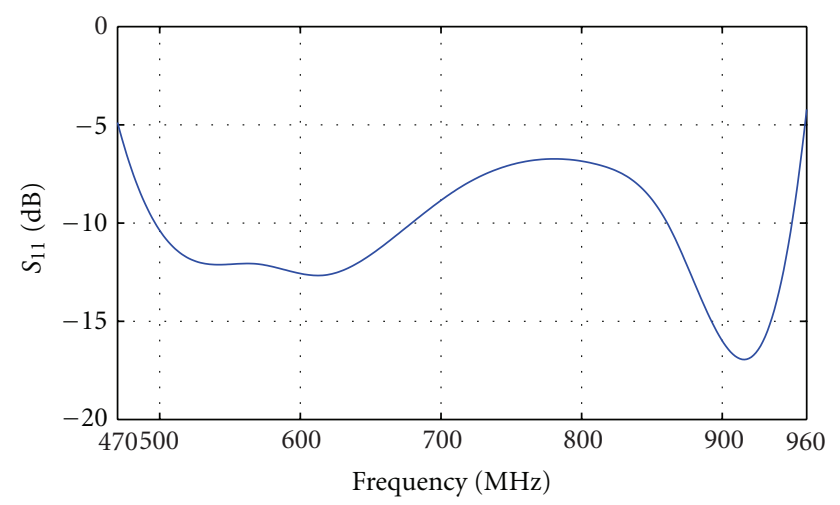

FIGURE 14: Return loss of the dual-polarized antenna.

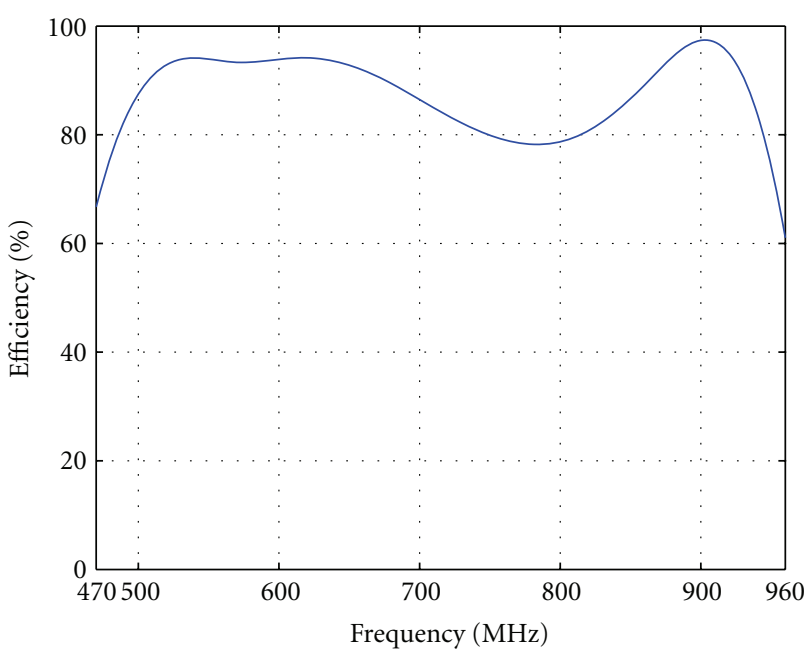

FIgURE 15: Efficiency of the dual-polarized antenna.

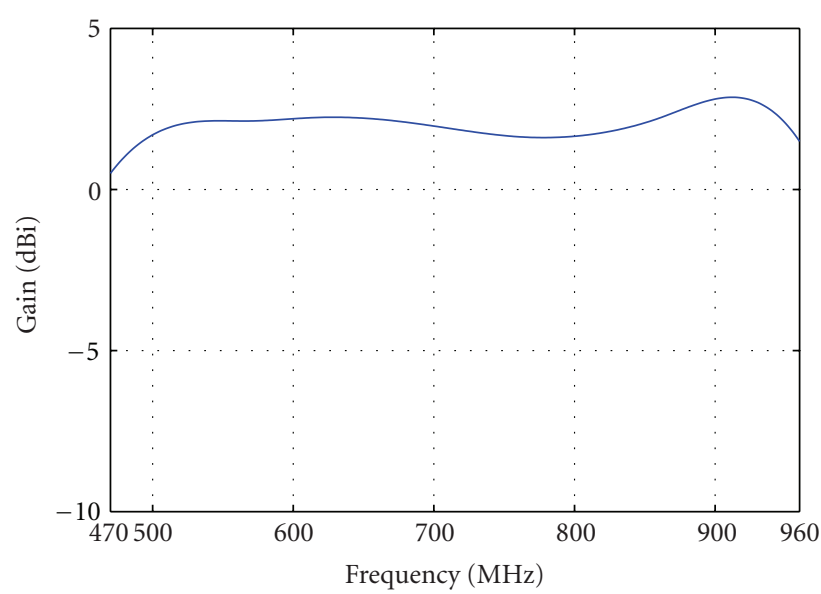

FIGURE 16: Peak gain of the dual-polarized antenna.
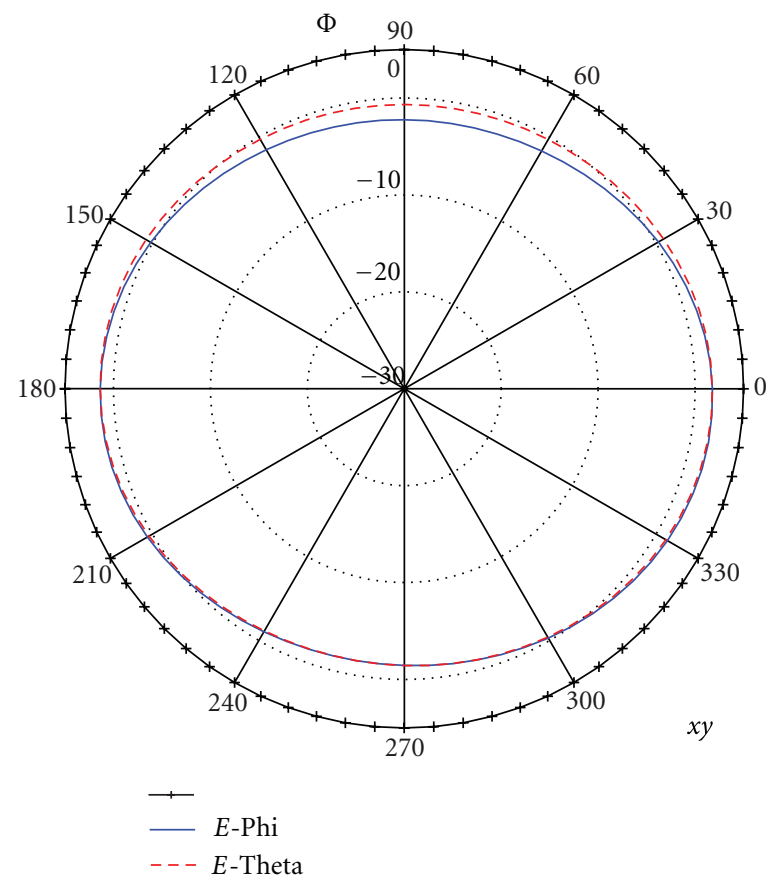

FIGURE 17: Copolar and cross-polar radiation patterns of the dualpolarized antenna at $600 \mathrm{MHz}$.

the above presented results of single antennas. However, as expected, the radiation patterns of the orthogonal antennas are significantly affected by MIMO configurations. The overall radiation patterns of MIMO antennas are the summations of the radiation patterns of the orthogonal antennas. Figure 19 shows the copolar and cross-polar components of the radiation patterns of two orthogonal antennas at $600 \mathrm{MHz}$ in the plane of the antennas. The orthogonal antennas are $1 \mathrm{~cm}$ apart from each other. The copolar and cross-polar components are exactly the same.

\section{Digital TV Antennas with EBG Structures}

In order to further increase the peak gain of the new digital TV antenna, a rectangular EBG structure was added to the 


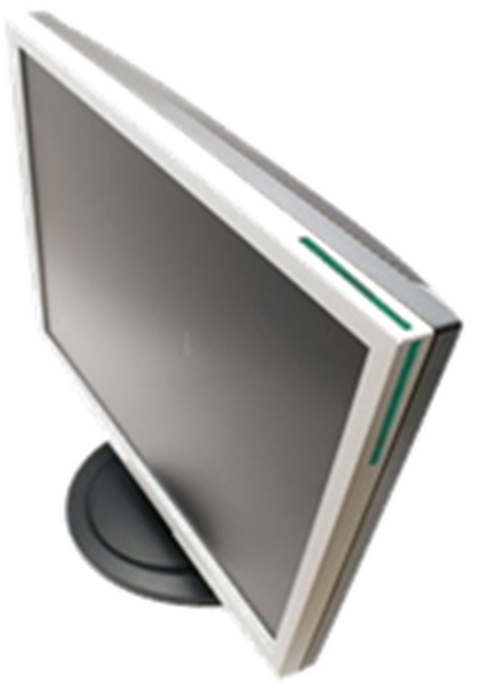

Figure 18: Two orthogonal antennas on a TV set with two different feed points for MIMO configurations.

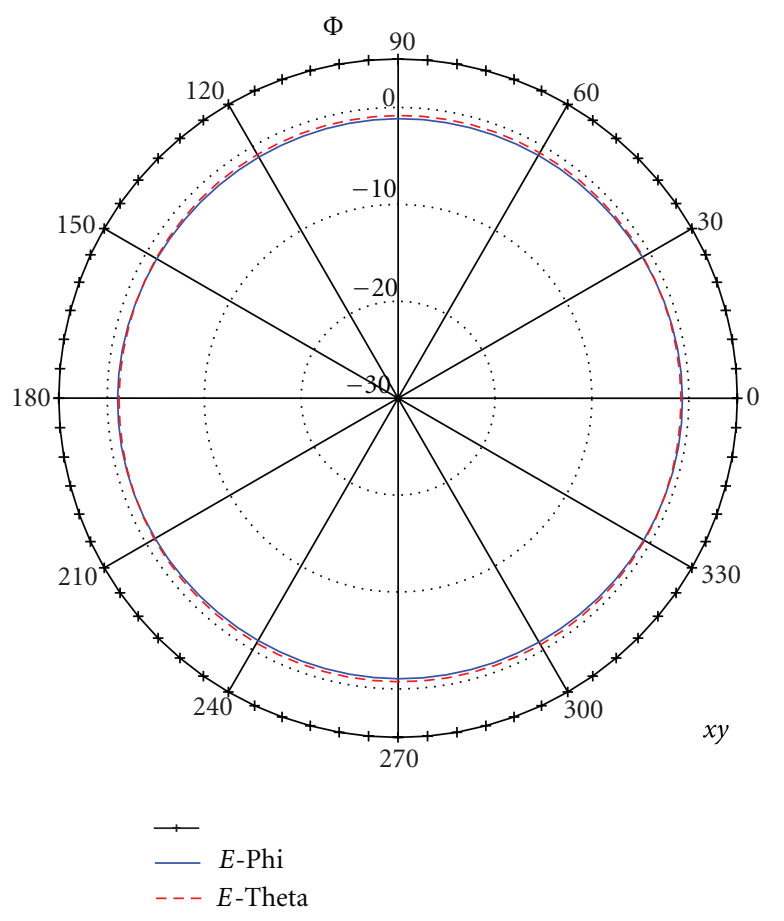

FIGURE 19: Radiation patterns of two orthogonal antennas at $600 \mathrm{MHz}$.

antenna. The EBG consists of $3 \times 11$ elements as shown in Figure 20. The dimensions of each element are $24 \times$ $24 \mathrm{~mm}$, and the gap between each two elements is $4 \mathrm{~mm}$. The dimensions of the EBG ground plane are $10 \times 32 \mathrm{~cm}$, and it is located at $12 \mathrm{~mm}$ under the EBG elements. The antenna is located at $9 \mathrm{~mm}$ above the EBG elements. Figure 21 shows the return loss of the new digital TV antenna with the EBG structure. The return loss is better than $-10 \mathrm{~dB}$ over most of the band. Figure 22 shows the efficiency of the EBG digital

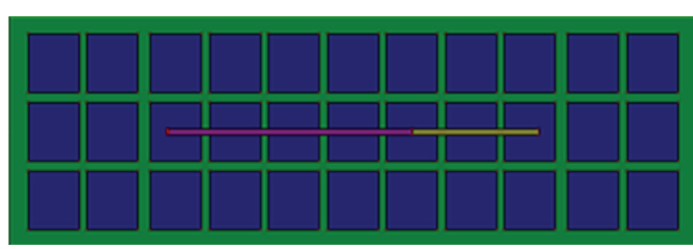

FIgURE 20: The new antenna on the EBG structure.

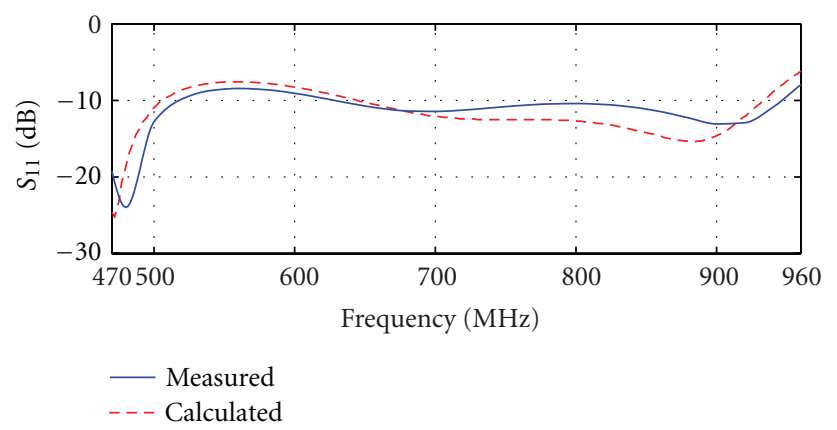

FIGURE 21: Return loss of the EBG digital TV antenna.

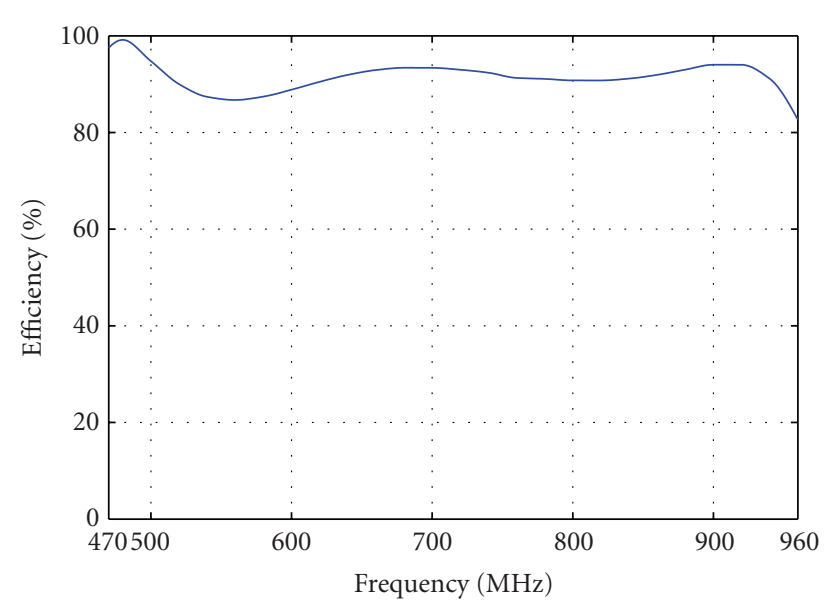

FIGURE 22: Efficiency of the EBG digital TV antenna.

TV antenna. The antenna efficiency exceeds $90 \%$ over most of the band. The peak gain of the antenna is shown in Figure 23, which is more than $5 \mathrm{dBi}$ over most of the band.

\section{Conclusions}

A novel internal antenna was developed for indoor reception of UHF terrestrial digital TV broadcasting. The overall size of the antenna was $1.75 \mathrm{~cm}^{3}$ and its weight was less than $1 \mathrm{gm}$. This was the overall volume of the antenna because it did not require an additional ground plane, a matching circuit, or any other components. The new digital TV receiving antenna was made of a flexible material, and it could be bent or folded and shaped in any form. It could be fully embedded inside TV sets and portable computers. The new antenna had a bandwidth of more than $68 \%$. It could also cover the bands of GSM and CDMA, which is advantageous in case of 


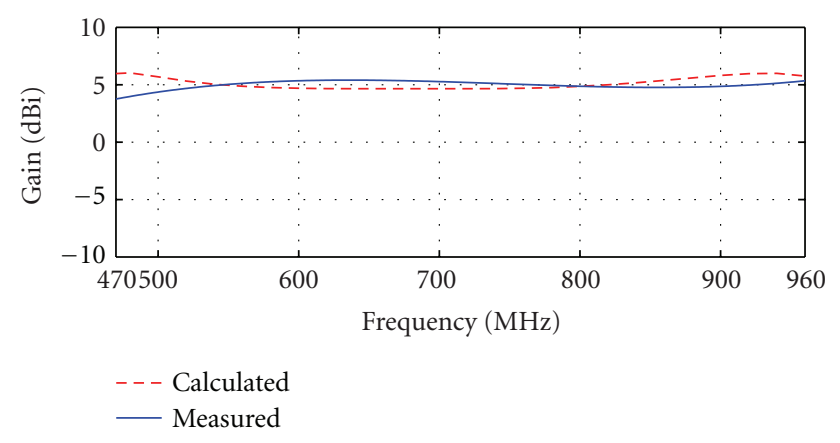

FIgURE 23: Peak gain of the EBG digital TV antenna.

portable computers. The peak gain of the new internal digital TV antenna was about $0 \mathrm{dBi}$ over the whole UHF band, and the average efficiency was more than $45 \%$. The peak gain was increased to about $2 \mathrm{dBi}$ by increasing the width and the thickness of the antenna. Increasing the antenna size also increased the overall efficiency to more than $80 \%$ over most of the UHF band. The peak gain could be further increased to more than $5 \mathrm{dBi}$ by adding EBG (electromagnetic bandgap) structures to the new digital TV antenna. The EBG structure consisted of $3 \times 11$ elements. The EBG also improved the return loss of the antenna and increased its efficiency to around $90 \%$.

The new internal digital TV antenna was linearly polarized. It could be easily modified in order to make it sensitive to two perpendicular polarizations, which is a very important factor in all indoor applications. Dual-polarization could be accomplished by combining two orthogonal antennas with a common feed point. Dual-polarization could also be achieved by two orthogonal antennas with two different feed points for multi-input, multioutput (MIMO) techniques.

\section{Acknowledgment}

The authors would like to thank Mohamed Osama, Lamiaa Mamdouh, and Mahetab Salama for their great effort in preparing this paper.

\section{References}

[1] R. C. Johnson and H. Jasik, Antenna Engineering Handbook, McGraw-Hill Book Company, New York, NY, USA, 1984.

[2] S. Kashihara and F. Kuroki, "J-shaped monopole antenna array as an antenna for terrestrial digital broadcasting at UHF band," in Proceedings of the IEEE MTT-S International Microwave Symposium (IMS '09), pp. 293-296, Boston, Mass, USA, June 2009.

[3] F. Kuroki and H. Ohta, "L-shaped monopole array for terrestrial broadcasting reception in the UHF band," in Proceedings of the 37th European Microwave Conference (EUMC '07), pp. 1070-1073, Munich, Germany, October 2007.

[4] F. Kuroki, H. Ohta, M. Yamaguchi, and E. Suematsu, "Wallhanging type of self-complementary spiral patch antenna for indoor reception of digital terrestrial broadcasting," in Proceedings of the IEEE MTT-S International Microwave Symposium Digest, pp. 194-197, San Francisco, Calif, USA, June 2006.
[5] J. Kim, G. Kim, W. Seong, and J. Choi, "A tunable internal antenna with an epsilon negative zeroth order resonator for DVB-H service," IEEE Transactions on Antennas and Propagation, vol. 57, no. 12, pp. 4014-4017, 2009.

[6] L. Huang and P. Russer, "Tunable antenna design procedure and harmonics suppression methods of the tunable DVB-H antenna for mobile applications," in Proceedings of the 37th European Microwave Conference (EUMC '07), pp. 1062-1065, Munich, Germany, October 2007.

[7] L. Huang and P. Russer, "Electrically tunable antenna design procedure for mobile applications," IEEE Transactions on Microwave Theory and Techniques, vol. 56, no. 12, pp. 27892797, 2008.

[8] C. M. Chiang, A. Yang, and C. C. Chien, "Active Digital TV Antenna," US Patent No. 0066116, 2008.

[9] J. Liang and H. Y. D. Yang, "Radiation characteristics of a microstrip patch over an electromagnetic bandgap surface," IEEE Transactions on Antennas and Propagation, vol. 55, no. 6, pp. 1691-1697, 2007.

[10] F. Yang, X. X. Zhang, X. Ye, and Y. Rahmat-Samii, "Wide-band E-shaped patch antennas for wireless communications," IEEE Transactions on Antennas and Propagation, vol. 49, no. 7, pp. 1094-1100, 2001.

[11] M. Sanad, F. Yang, Y. Rahmat-Samii, and X. X. Zhang, "Comments on wide-band E-shaped patch antennas for wireless communications," IEEE Transactions on Antennas and Propagation, vol. 51, no. 9, pp. 2541-2542, 2003.

[12] M. Sanad and N. Hassan, "A resonant handset antenna that can cover all bands of UHF mobile TV, GSM and CDMA without using matching circuits," in Proceedings of the IEEE International Symposium on Antennas and Propagation (APSURSI'10), pp. 1-4, July 2010.

[13] M. Sanad and N. Hassan, "An internal EBG antenna for indoor reception of UHF terrestrial digital TV broadcasting," in Proceedings of the 10th Mediterranean Microwave Symposium (MMS '10), pp. 178-181, August 2010.

[14] M. Sanad and N. Hassan, "A 470 to $960 \mathrm{MHz}$ resonant antenna: covering uhf mobile TV and CDMA/GSM without tuning circuits," Microwave Journal, vol. 53, no. 11, pp. 56-72, 2010.

[15] M. Sanad and N. Hassan, "A novel dual resonant antenna configuration for mobile laptop, notebook and palmtop computers," in Proceedings of the IEEE International Symposium on Antennas and Propagation, pp. 1-4, Toront, canada, July 2010.

[16] http://www.imst.com/en/home.php.

[17] http://www.eicta.org/index.php?id=33\&id_article=152. 

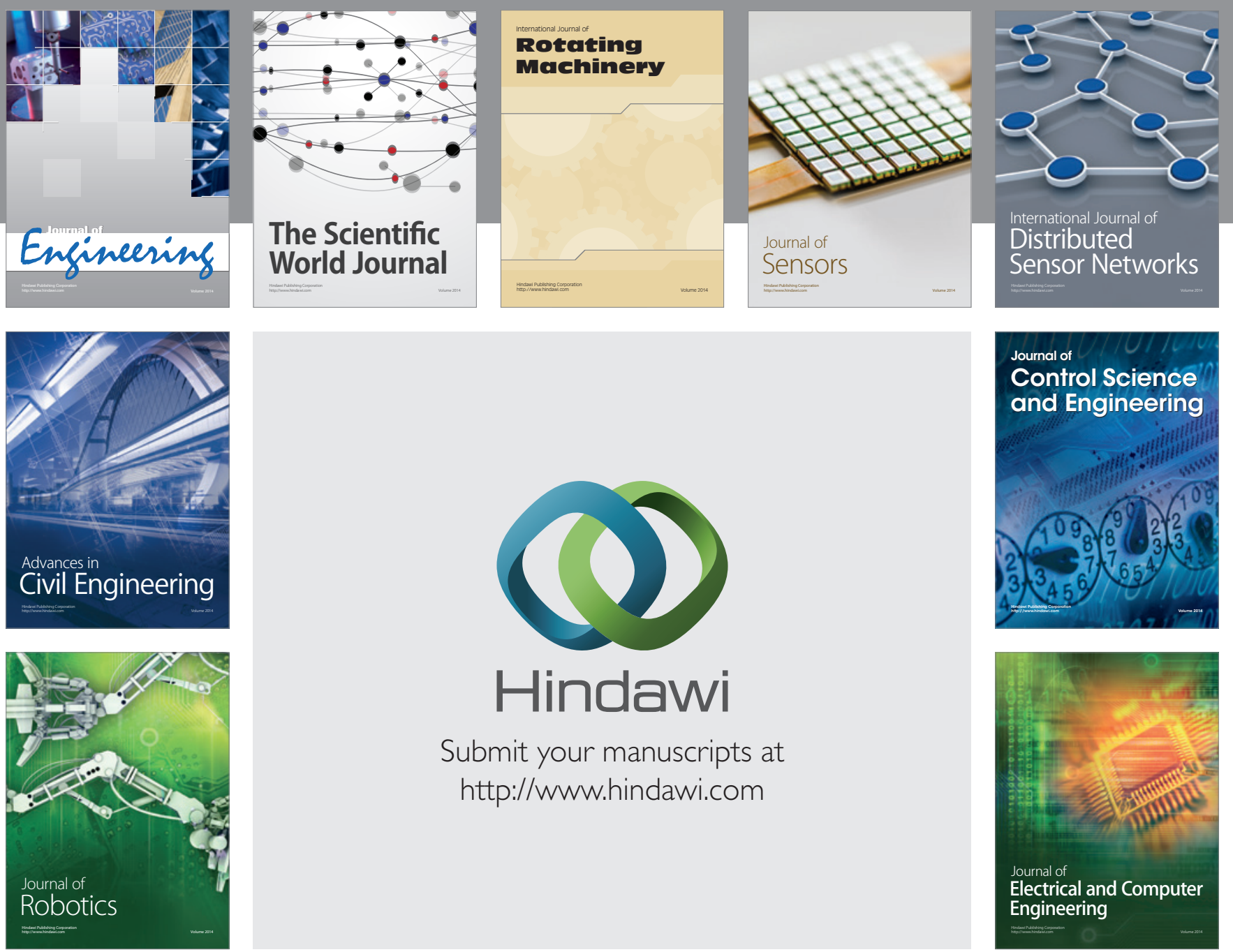

Submit your manuscripts at

http://www.hindawi.com
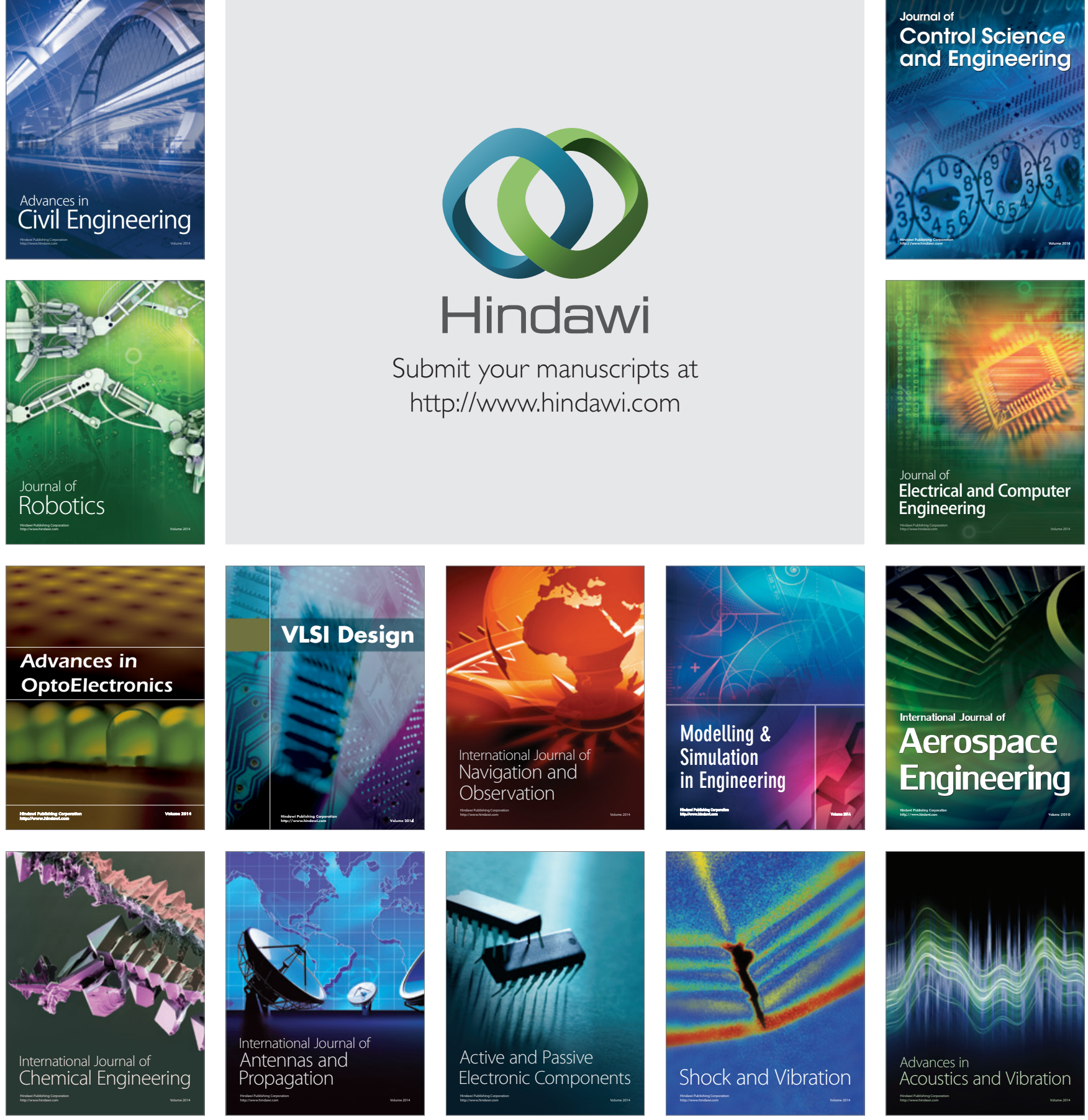